\title{
SIMONE DE BEAUVOIR EN ARGENTINA: EL ROL DE LAS EDITORIALES Y DE LAS TRADUCCIONES EN LA RECEPCIÓN DE SU OBRA
}

\author{
SIMONE DE BEAUVOIR IN ARGENTINA: ROLES OF PUBLISHING HOUSES \\ AND TRANSLATIONS IN THE RECEPTION OF HER WORK
}

\section{SIMONE DE BEAUVOIR NA ARGENTINA: O PAPEL DAS EDITORAS E DAS TRADUÇÕES NA RECEPÇÃO DE SEU TRABALHO}

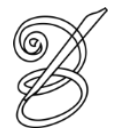 \\ Beatriz Emilce CAGNOLATI ${ }^{1}$ \\ Universidad Nacional de La Plata, Argentina \\ María Luisa FEMENÍAS ${ }^{2}$ \\ Universidad Nacional de La Plata, Argentina \\ Universidad Nacional de Quilmes, Argentina \\ Jovanka VUKOVIC ${ }^{3}$ \\ Universidad Nacional de La Plata, Argentina
}

\begin{abstract}
Resumen: El presente artículo — enmarcado en la traductología, el feminismo filosófico y la teoría de género trata sobre la amplia y rápida difusión de la influyente obra de Simone de Beauvoir en la cultura argentina de los años 50 y de los 70 con proyección a toda América Latina y España, gracias a la labor de numerosas editoriales radicadas en Buenos Aires, que emprendieron la tarea de traducción con intelectuales de renombre (CORBÍ SÁEZ, 2010, p.77). El análisis de las traducciones habilita a plantear cuestiones concomitantes a la recepción teóricoconceptual y a las fluctuaciones de sentido del léxico, por cuestiones epocales (FOUCAULT, 1992, p.128-129). Para el desarrollo de tales temáticas, este trabajo presenta, por un lado, una revisión de los casos significativos de terminología y sintaxis en Le deuxième sexe (1949), obra fundamental y vigente en el ámbito de los Estudios de Género. Al respecto, se seleccionaron casos con mecanismos discursivos que dan cuenta tanto de la presencia del sexo-género femenino como de su opacamiento, que fueron analizados desde un enfoque traductológico, contrastando la obra original en francés y la primera traducción de Pablo Palant (1954) de El segundo sexo. Por otro lado, se ofrece un recorrido de las otras obras de Beauvoir, sus traducciones y de quienes llevaron a cabo esa tarea, con un relevamiento exhaustivo en apéndice.
\end{abstract}

Palabras clave: Traducciones argentinas. Mecanismos discursivos. Editoriales. Simone de Beauvoir.

Abstract: The present paper based on traductology, philosophical feminism and Gender Studies deals with the wide, quick and influential diffusion of Simone de Beauvoir's work, not only in culture of the 50' and the 70' but also along Latin American countries and Spain thanks to the publishing houses settled in Buenos Aires that commissioned the translation of her works to the well-known intellectuals of that time. (CORBÍ SÁEZ, 2010, p.77). Translation analysis enables to introduce concomitant issues not only on the theoretical and conceptual reception and the philosophical development but also on the construction of new comprehensive categories that show lexical fluctuations and epochal influences (FOUCAULT, 1992, p.128-129). In order to analyze these issues, the present paper presents the revision of significant cases related to terminology and syntax in Le deuxième sexe (1949), as it is well known, a fundamental and valid work still taken into consideration in Gender Studies. To this respect, on the one hand discourse mechanisms put in evidence either the visibility or invisibility of the femenine sex-gender, analyzed from a traductological point of view, always confronting the original French edition which first

CAGNOLATI, FEMENÍAS, VUKOVIC. Simone de Beauvoir en Argentina: el rol de las editoriales y de las traducciones en la recepción de su obra

Belas Infiéis, v. 8, n. 2, pp. 31-49, 2019. DOI: 10.26512/belasinfieis.v8.n2.2019.24372 
translation into Spanish is due to Pablo Palant (1954) as El segundo sexo. On the other hand, an exhaustive survey of Beavouir's translated works, and reference to the translators is offered in the appendix.

Keywords: Argentine translations. Discourse mechanisms. Publishing houses. Simone de Beauvoir.

Resumo: O presente artigo - enquadrado em tradutologia, feminismo filosófico e teoria de gênero - trata da ampla e rápida difusão da influente obra de Simone de Beauvoir na cultura argentina dos anos 50 e 70, com uma projeção para toda América Latina e Espanha, graças ao trabalho de numerosas editoras sedeadas em Buenos Aires, que iniciaram a tarefa de tradução com intelectuais de renome. (CORBÍ SÁEZ, 2010, p. 77). A análise das traduções possibilita levantar aspectos concomitantes à recepção teórico-conceitual e às flutuações de sentido do léxico, por questões das épocas (FOUCAULT, 1992, p. 128-129). Para o desenvolvimento de tais temas, este trabalho apresenta, por um lado, uma revisão dos casos significativos de terminologia e sintaxe em Le deuxième sexe (1949), uma obra fundamental e em vigor no âmbito dos Estudos de Gênero. A esse respeito, selecionaramse casos com mecanismos discursivos que dão conta tanto da presença do sexo-gênero feminino quanto de sua ofuscação, os quais foram analisados numa abordagem tradutológica, contrastando a obra original em francês com a primeira tradução de Pablo Palant (1954) de O segundo sexo. Por outro lado, oferece um percurso pelas outras obras de Beauvoir, suas traduções e aqueles que realizaram essa tarefa, com uma pesquisa abrangente no apêndice.

Palavras chave: Traduções argentinas. Mecanismos discursivos. Editoras. Simone de Beauvoir.

RECEBIDO EM: 15 de julho de 2018

ACEITO EM: 02 de novembro de 2018

PUBLICADO EM: abril 2019

CAGNOLATI, FEMENÍAS, VUKOVIC. Simone de Beauvoir en Argentina: el rol de las editoriales y de las traducciones en la recepción de su obra

Belas Infiéis, v. 8, n. 2, pp. 31-49, 2019. DOI: 10.26512/belasinfieis.v8.n2.2019.24372 


\section{Introducción}

- Cómo hacer un balance de la obra de Simone de Beauvoir? Como se sabe, sus novelas, su ensayística y su filosofía se enlazan con el pensamiento feminista surgido tras el

movimiento sufragista y con el de las mujeres marxistas, críticas de preguerra. A partir de la década de los sesenta, el feminismo de Simone de Beauvoir y la consolidación del Movimiento de Liberación Femenina se convirtieron en movimientos político-sociales y filosóficos, que fueron fuente de inspiración de casi todos los conceptos y desarrollos del feminismo posterior. Por eso, nuestras investigaciones sobre la recepción y la traducción de la obra de Simone de Beauvoir - en especial Le deuxième sexe (1949) - en Argentina y en Latinoamérica ponen de manifiesto el interés y el impacto que produjo su pensamiento y su estilo narrativo, no solo desde una perspectiva teórico-conceptual, sino también como proyecto estético-constructivo.

En ese marco, la labor de traducción y difusión editorial realizada en nuestro país tuvo una relevancia fundamental puesto que posibilitó mostrar la estética y el pensamiento beauvoirianos a un vasto público de mujeres hispanohablantes. Argentina inició esa tarea antes que otros países latinoamericanos e incluso que España, donde el régimen totalitario franquista había proscripto a los filósofos existencialistas, incluidos Beauvoir y Sartre (CORBÍ SÁEZ, 2010, p. 77).

En Argentina, entre las décadas de los 50 y los 70, intelectuales de renombre tradujeron las obras de Beauvoir, contribuyendo a consolidar los feminismos en la región. Actualmente, los estudios de género iluminan algunos problemas que no solo afectan su traducción-recepción sino que se convierten, sobre todo a partir de la década de los ochenta, en un problema de interés categorial. En efecto, las traducciones introducen cuestiones concomitantes tanto a la recepción teórico-conceptual como a su elaboración filosófica, recogiendo además el problema de las fluctuaciones lexicales y de las influencias epocales (FOUCAULT, 1992, p. 128-129), en la construcción de nuevas categorías comprensivas.

En este artículo nos preguntamos de qué modo se relacionan las tareas de traducción y difusión con la recepción y el horizonte de sentido, en el que participaron intelectuales, lectoras, traductoras y escritoras. Para responder a estas cuestiones, en lo que sigue desarrollaremos dos aspectos: 1) la difusión y recepción de la obra traducida de Simone de Beauvoir en Argentina y 2) la revisión de casos significativos de terminología y sintaxis en Le deuxième sexe/El segundo sexo. A los efectos de completar nuestra tarea, agregaremos un apéndice en el que 
relevamos — con la colaboración de Smaldone (2016) — quiénes tradujeron la obra, su edición, etc. En todos los casos consideramos clave la red teórico-conceptual, propia de la filosofía beauvoiriana, enmarcando nuestra investigación actual en la traductología, el feminismo filosófico y la teoría de género.

\section{Difusión y recepción de la obra de Simone de Beauvoir en Argentina}

El proceso de recepción de la obra de Simone de Beauvoir en Argentina (y por extensión en el mundo hispanohablante) involucra especialmente a las editoriales locales y sus políticas. Por eso exploramos, en primer término, su función en la decisión de emprender la tarea de traducción (TOURY, [1995] 2004, p.100).

En un contexto de moda existencialista, Buenos Aires (Argentina) junto con Montevideo (Uruguay), se erigieron en las dos ciudades sudamericanas con mayor influencia de la cultura francesa. En Buenos Aires, la traducción de toda la obra de Beauvoir tiene como antecedente el artículo «Literatura y metafísica», publicado en la revista Sur (1947). Sur (19311992) había sido fundada por Victoria Ocampo y María Rosa Oliver y, bajo la dirección de la

34 primera, contó con un importante equipo de redactores/as y colaboradores/as, en su mayoría figuras destacadas de la literatura y del pensamiento ensayístico de la época, entre quienes se encontraban, además de sus fundadoras, la poeta chilena Gabriela Mistral y Silvina Ocampo, hermana de Victoria, también escritora. Sur se convirtió en una revista emblemática de Argentina, cuya circulación entre el público hispanohablante constituyó un puente con el mundo (PARODI LISI, 1987; KING, 1989; ALTAMIRANO; MYERS, 2008). Así, «Literatura y metafísica» (1947) fue una de las primeras producciones beauvoirianas traducida al castellano por María Rosa Oliver, y publicada al año siguiente de su aparición en Les Temps Modernes. En 1948, el artículo formó parte del libro L'existentialisme et la sagesse des nations, que se publicó en Argentina en 1965, en la editorial Siglo XX, traducido por el ensayista Juan José Sebreli.

Con el interés de difundir novedades culturales, Ocampo creó también el sello editorial Sur (1933) - luego Editorial Sur Sociedad Anónima Comercial, Industrial y Financiera (1961) —, lo que permitió la difusión de escritoras argentinas poco conocidas en la época y de figuras consagradas, como Virginia Woolf, traducidas al castellano, al alcance de un vasto público, ampliando los objetivos de la revista y favoreciendo los cambios en el campo cultural e intelectual argentino de entonces (WILLSON, 2004, p. 85; 2007). 
Además de Sur, a partir de la década del 50 otras editoriales radicadas en Buenos Aires Ariadna, Emecé, Psique, Siglo Veinte, Schapire y Sudamericana - difundieron las obras existencialistas en lengua castellana, en particular las de Beauvoir. Destacamos que las traducciones-publicaciones se hacían en un lapso mínimo, entre su aparición en francés y en castellano, lo que da cuenta del interés del público receptor hispanohablante y del editorial en satisfacerlo (CAGNOLATI, FORTE MÁRMOL, GENTILE, VIEGUER, 2010, p.13-15). Se trataba de un público receptor femenino, que no siempre dominaba el idioma francés, - como sí lo hacían las elites culturales, que ya la habían leído - pero muy comprometido con la consolidación de sus derechos políticos, sociales y culturales (WILLSON, 2004, p. 84-85).

Respecto de las editoriales, Sudamericana publica Los mandarines (1958) solo cuatro años después de su aparición en Francia, donde Les Mandarins (1954) había recibido el Premio Goncourt. Para esa misma época (1958) aparece en el sello editorial Gallimard el primer ensayo autobiográfico de Simone de Beauvoir, Mémoires d'une jeune fille rangée, publicado en castellano por Sudamericana en 1959 con el título Memorias de una joven formal, en traducción de Silvina Bullrich. Beauvoir se inserta así en el sistema cultural receptor como modelo escriturario, por ejemplo, en Mis Memorias (1980) de Silvina Bullrich o en Mundo, mi casa (1965) de María Rosa Oliver, ambas escritoras y traductoras de Beauvoir (SMALDONE, 2017).

En cuanto a sus novelas, Les belles images se publicó en la editorial Sudamericana en 1967 con el título Hermosas imágenes, obra de la que se realizó en España una nueva traducción en 1981, bajo el título Las bellas imágenes (FERRERO, 2010). En 1968, nuevamente Sudamericana difunde la serie de relatos reunidos en La mujer rota - que contiene un relato homónimo - inmediatamente después de la publicación del original La Femme rompue, que reúne los relatos L'Âge de discrétion y Monologue, editados por Gallimard. A principio de los años 70 y en la década de los 80, Sudamericana alcanza gran protagonismo por la difusión de las traducciones La vejez (1970), Final de cuentas (1972) y La fuerza de las cosas (1973).

La circulación de las obras de Simone de Beauvoir, su recepción local en general y del público feminista en particular fueron sumamente importantes (VIEIRA BORGES, 2013); tanto que, a lo largo de los años 80, finalizando la última dictadura militar en Argentina (1976-1983), Sudamericana reedita La plenitud de la vida (1980), con gran impacto tanto en la cultura nacional como en la de otros países sudamericanos, también bajo regímenes dictatoriales. En el año 1983, la misma editorial publicó una traducción de La cérémonie des adieux suivi 
d'Entretiens avec Jean-Paul Sartre (Août - septembre 1974), con el título de La ceremonia del adiós, seguido de Conversaciones con Jean-Paul Sartre, agosto-septiembre de 1974.

Poco después, por diversas razones - muchas vinculadas a nuestra inestabilidad económica — las editoriales argentinas, paradigmáticamente EUDEBA, se ven desplazadas por las españolas, algunas de las cuales (como Alianza) adquirieron sus fondos editoriales, reeditando con su sello buena parte de las traducciones de Beauvoir (y otros) al español, tema que escapa al objetivo de este artículo.

\subsection{Relevamiento de quienes tradujeron la obra}

Gran parte de la recepción beauvoiriana se construyó sobre la base de las traducciones realizadas por escritoras y escritores de renombre nacional, como la mencionada Silvina Bullrich. Autora prolífica, Bullrich escribió novelas, relatos y guiones para el cine argentino y enseñó literatura francesa en la Universidad Nacional de La Plata, integrando un grupo de reconocidas escritoras de la llamada Generación del 60 y 70, entre las cuales se encuentran también Marta Lynch y Beatriz Guido. (MUCCI, 2003). Por su parte, el destacado ensayista y

36 crítico literario Juan José Sebreli — columnista de la revista Sur y de otras revistas literarias como Contorno, dirigida por David Viñas (CORREAS, 2007, p. 22) — tradujo también algunos ensayos de Beauvoir, entre ellos, El existencialismo y la sabiduría de los pueblos, retraducido en el año 2008 por Horacio Pons y publicado por Edhasa.

Otros nombres relevantes circulan como traductores de Beauvoir. Entre ellos, el periodista y escritor Hellén Ferro (1919-2011) quien tradujo Le sang des autres; Floreal Mazia (1920-1990), traductor literario autodidacta, quien hizo lo propio con la obra de teatro Las bocas inútiles; Francisco Jorge Solero, escritor, que tradujo el ensayo filosófico Pour une morale de l'ambiguïté; José Bianco, escritor, tradujo Les belles images. (FERRERO, 2010). Además, el filósofo Ezequiel de Olaso tradujo La force des choses; María Elena Santillán, Une mort très douce; Dolores Sierra, y Néstor Sánchez, tradujeron La mujer rota, mientras que Aurora Bernárdez, escritora, esposa y albacea de Julio Cortázar, tradujo La vieillesse en 1970, mientras que la ensayista, poeta, crítica literaria y profesora uruguaya, Ida Vitale se encargó de la traducción de Tout compte fait, aparecida en 1972.

Como ya señalamos, una consideración especial merece el extenso ensayo Le deuxième sexe (Paris, Gallimard, 1949) que aparece en las librerías de Buenos Aires, en 1954, con el título El segundo sexo por iniciativa de Ediciones Psique. Lo tradujo el argentino Pablo Tischkovsky Blant 
(1914-1975), conocido como Pablo Palant, escritor de obras de teatro y guionista, con formación en abogacía. En lo que sigue, nos centraremos en esta primera traducción, porque permite comprender el contexto de recepción y las influencias de época.

\section{Revisión de casos de terminología y sintaxis en Le deuxième sexel El segundo sexo}

En este apartado comentaremos algunos ejemplos que consideramos paradigmáticos, en relación con la comprensión y reexpresión en castellano de palabras y conceptos de Le Deuxième Sexe, resignificados desde la perspectiva actual de género.

\subsection{Femme y femelle}

Los vocablos femme y femelle recorren la obra de Beauvoir y no es casual que la autora inicie el primer capítulo de Le Deuxième Sexe definiéndolos y explicándolos ampliamente, de modo de determinar el alcance de cada uno de ellos.

Precisamente tomamos las primeras palabras de la «Première partie. Destin, Chapitre Premier. Les données de la biologie »:

(1) La femme? c'est bien simple, disent les amateurs de formules simples : elle est une matrice, un ovaire; elle est une femelle : ce mot suffit à la définir. Dans la bouche de l'homme, l'épithète "femelle» sonne comme une insulte; pourtant il n'a pas honte de son animalité, il est fier au contraire si l'on dit de lui «C'est un mâle !» Le terme "femelle» est péjoratif non parce qu'il enracine la femme dans la nature, mais parce qu'il la confine dans son sexe; et si ce sexe paraît à l'homme méprisable et ennemi même chez les bêtes innocentes, c'est évidemment à cause de l'inquiète hostilité que suscite en lui la femme; cependant il veut trouver dans la biologie une justification de ce sentiment. (BEAUVOIR, 1949, I, p. 45).

A continuación, consignamos la traducción al castellano del fragmento anterior «Primera Parte. Destino. Capítulo Primero. Los elementos de la biología», de Palant:

(2) ¿La mujer? Es muy sencillo, dicen los aficionados a las fórmulas simplistas: es una matriz, un ovario; es una hembra, y basta esa palabra para definirla. En boca del hombre el epíteto "hembra" suena como un insulto y, sin embargo, no tiene vergüenza de su propia animalidad y se siente orgulloso, por el contrario, si dicen de él que "¡es un macho!" El término "hembra" no es peyorativo por el hecho de que enraiza a la mujer en la Naturaleza, sino porque la confina dentro de los límites de su sexo, y si ese sexo le parece al hombre despreciable y enemigo aun entre las bestias inocentes es, sin duda alguna, a causa de la inquieta hostilidad que suscita en él la mujer, a ese sentimiento. (BEAUVOIR. Trad. de Palant, 1954).

CAGNOLATI, FEMENÍAS, VUKOVIC. Simone de Beauvoir en Argentina: el rol de las editoriales y de las traducciones en la recepción de su obra

Belas Infiéis, v. 8, n. 2, pp. 31-49, 2019. DOI: 10.26512/belasinfieis.v8.n2.2019.24372 
Este fragmento inicial muestra el alcance semántico de femme y femelle y se centra en la distinción imprescindible para confrontar tanto con el «sentido común» misógino como con la reelaboración de dicho «sentido común», que subyace a los discursos de diferentes disciplinas, como la biología. Dicha distinción conceptual tiene en Beauvoir la finalidad de poner en evidencia que, así como lo que entendemos por «mujer» es producto de un entramado social determinado, también la idea de «varón» corresponde a una construcción cultural. Precisamente, la distinción y la definición de los términos «mujer» (la femme) y «hembra» (la femelle), están en la línea de la perspectiva desnaturalizante que despliega Simone de Beauvoir. En efecto, para ella el cuerpo sexuado debe entenderse como «cuerpo vivido» o, en otras palabras, cómo cada quien vive la sexualidad de su cuerpo, que es condición material de la existencia, pero no la única; inciden también el color de la piel, la clase social, el lugar de nacimiento, etc. Como sostiene María Luisa Femenías, Simone de Beauvoir «diseñó y describió un concepto que sólo más adelante el feminismo denominó 'género', en términos de construcción cultural de la feminidad sobre el sexo-hembra, y de lo masculino sobre el sexomacho» (FEMENÍAS, 2000; p. 40-41; 2008, p. 34-35).

Ahora bien, en cuanto al proceso de traducción referido a los términos femme y femelle, la reexpresión mediante las designaciones «mujer»y «hembra», respectivamente, recubre virtualidades similares en ambas lenguas y sentidos análogos en ambos textos.

\subsection{Travesti-travestie}

En la misma época en que Beauvoir publica la obra Le deuxième sexe y Pablo Palant la traduce al castellano, el diccionario de lengua francesa Larousse Classique Illustré. Nouveau Dictionnaire Encyclopédique (1951) categoriza a travesti como adjetivo (travesti-e), con el significado de travestido o disfrazado bajo la apariencia de otro sexo, y como sustantivo masculino que remite al traje de disfraz (CAGNOLATI; FEMENÍAS; SMALDONE, 2015). En cuanto al verbo travestir, su primera acepción está referida a disfrazarse con el ropaje de otro sexo (un varón que se viste de mujer, por ejemplo) y, de manera figurada, remite a la idea de imitación burlesca pero también a la de equivocación o mala interpretación (de un pensamiento, por ejemplo). En cualquier caso, estas definiciones no expresan la inversión de los rasgos sexuales entendidos como naturales desde un punto de vista biologicista. 
Veamos un ejemplo del original en francés:

(3) Cependant l'homosexualité n'apparaît pas toujours, quand il s'agit d'une femme dominatrice, comme une solution entièrement satisfaisante ; puisqu'elle cherche à s'affirmer, il lui déplaît de ne pas réaliser intégralement ses possibilités féminines; les relations hétérosexuelles lui semblent à la fois une diminution et un enrichissement ; en répudiant les limitations impliquées par son sexe, il se trouve que d'une autre manière elle se limite. De même que la femme frigide souhaite le plaisir tout en le refusant, la lesbienne voudrait souvent être une femme normale et complète, tout en ne le voulant pas. Cette hésitation est manifeste dans le cas de la travestie étudiée par Stekel. (BEAUVOIR, 1949, II, p. 230).

En este pasaje, la cohesión nocional iniciada por homosexualité está representada por una sucesión de expresiones — femme dominatrice, elle, luí, ses possibilités féminines (...), la lesbienne - siendo la travestie étudiée par Stekel el último eslabón de la cadena referencial.

Como veremos a continuación, Palant elige la palabra «invertida» para dar cuenta de travestie:

(4) Cuando se trata de una mujer dominadora, sin embargo, la homosexualidad no siempre se presenta como una solución del todo satisfactoria; porque como busca afirmarse le desagrada no realizar integralmente sus posibilidades femeninas; las relaciones heterosexuales le parecen una disminución y un enriquecimiento a la vez, y al repudiar las limitaciones que implica su sexo, encuentra que de otro modo se limita. Así como la mujer frígida desea el placer al mismo tiempo que lo rechaza, la lesbiana quisiera ser a menudo una mujer normal y completa al mismo tiempo que no lo quiere. Esa vacilación se manifiesta en el caso de la invertida estudiado por Stekel. (BEAUVOIR. Trad. de Palant, 1954, II, p. 182).

La decisión del traductor rioplatense fue compartida por la posterior versión al castellano de García Puente (1999). Ambos traductores reformularon el participio pasado del verbo travestir en función de sustantivo femenino como «invertida», siendo esta una solución lingüístico-discursiva no exenta de la influencia ensayística político-literaria argentina.

Por su parte, la traducción española más reciente de Alicia Martorell (2011) propone «travestida»:

(5) No obstante, la homosexualidad no siempre aparece, cuando se trata de una mujer dominante, como una solución totalmente satisfactoria; ya que trata de afirmarse, le desagrada no desarrollar totalmente sus posibilidades femeninas; las relaciones heterosexuales le parecen a un tiempo una disminución y un enriquecimiento; al repudiar las limitaciones que implica su sexo, lo que hace es limitarse de otra manera. De la misma forma que la mujer frígida busca el deseo rechazándolo, la lesbiana muchas veces quisiera ser una mujer normal y completa, aún sin querer serlo. Esta duda se manifiesta en el caso de la travestida estudiada por Stekel. (BEAUVOIR. Trad. de Martorell, 2011, p. 525).

CAGNOLATI, FEMENÍAS, VUKOVIC. Simone de Beauvoir en Argentina: el rol de las editoriales y de las traducciones en la recepción de su obra Belas Infiéis, v. 8, n. 2, pp. 31-49, 2019. DOI: 10.26512/belasinfieis.v8.n2.2019.24372 
El Diccionario de la Lengua Española (2014) incorpora el sema «travesti» o «travestí» como segunda acepción de «travestido-a», indicando que se trata de la persona «que se viste y se caracteriza como alguien del sexo contrario».

Las tres traducciones comentadas conservan la trama nocional y cohesiva del texto original, aun cuando conjeturemos que en la obra de 1949 los conceptos lesbienne y travestie no estaban aún distinguidos con precisión.

Como observamos en la primera traducción de Le deuxième sexe del Río de La Plata, el caso de «la invertida» (la travestie), responde a las implicancias de las normas de la cultura meta. La divergencia que abre la traducción al castellano de travestie, obliga a actualizar y revisar las traducciones, al menos para atender ciertos conceptos o términos clave del pensamiento beauvoiriano. Cuando Simone de Beauvoir analiza los argumentos de los estudios de su época sobre la mujer homosexual, se refiere a su modo de «travestirse». Esto es, a la forma de vestirse, los gestos y los gustos que desarrolla la mujer lesbiana, que emulan el modelo masculino, aunque al mismo tiempo le reconoce rasgos femeninos (BEAUVOIR, 1949, II, p. 239). Por su parte, Judith Butler - crítica del pensamiento beauvoiriano (BUTLER, 1986, p.

40 35-49; FEMENÍAS, 2003, p. 17-53) - le adjudica un carácter esencialista sobre la base de una peculiar interpretación de la frase «no se nace mujer, se llega a serlo», en el marco de su concepción de la performance. Es decir, se trata de una performance hiperbolizada, para codificar el sexo-género como un constructo (BUTLER, 2000; FEMENÍAS, 2000). Sea como fuere, en el término beauvoiriano la travestie, no hay una «inversión», como lo indica la traducción al castellano de Palant, sino que, por el contrario, se acerca a los términos de Judith Butler, de «imitación burlesca» (mock) o, en el sentido en que más tarde entiende la «performatividad». En Traductología, la relación entre traducción y género ha evolucionado desde un primer paradigma binario, signado por el origen del activismo feminista, que reconoce la existencia de dos grupos diferenciados de personas - mujeres y varones - hacia un segundo paradigma caracterizado por la desestabilización del término género, que convoca una multiplicidad de corrientes derivadas de factores sociopolíticos — entre otros la diversidad de género, la analogía con los grupos minoritarios según su etnia y raza-, lo cual dificulta la identificación primaria de alguien como femenino o masculino y pone el acento en el género desde la noción de acto discursivo y contingente. (Von Flotow, 2007 p. 92, 94, 100). 


\subsection{Presencia del sexo-género femenino}

En el primer capítulo, se registran vocablos de la esfera del sexo-hembra: la hembra en sí misma (femelle/hembra), nombres de ejemplares hembra (femelle/hembra, biche/cierva, chienne/perra, guenon/mona, la reine des termites/reina de las termitas, tigresse/ tigresa, lionne/leona, entre otros), partes y características del cuerpo de la hembra (matrice/matriz, ovaire/ovario, ovule/óvulo, utérus/útero, menstruation/menstruación, règles/reglas, ménopause/menopausia), palabras del campo de la fecundación encarnada en el cuerpo de la hembra (gestation/gestación, grossesse/embarazo, embryon/embrión, foetus/feto, oeuf fécondé/huevo fecundando, accouchement/parto, allaitement/lactancia). A esta enumeración no exhaustiva, sumamos vocablos que nombran el género femenino (femme/mujer, fille/niña).

Una atención especial merece la palabra mère/madre, ya que reúne sexo-hembra y género femenino, en tanto evoca la función de procreación animal La mère expulse les ovules (1949, I, p. 67) / «La madre expulsa los óvulos» (1954, I, p. 53), pero también la responsabilidad social de la procreación:

(6) La liaison intime de la mère à l'enfant sera source pour elle de dignité ou d'indignité selon la valeur accordée à l'enfant et qui est très variable; cette liaison même, on l'a dit, sera reconnue ou non selon les préjugés sociaux (BEAUVOIR, 1949, I, p. 91).

(7) El vínculo íntimo entre la madre y el hijo será para ella fuente de dignidad o indignidad, según sea el valor acordado al niño, que es muy variable: ese mismo vínculo, se ha dicho, será reconocido o no según sean los prejuicios sociales (BEAUVOIR.Trad. de Palant, 1954, I, p. 73).

Desde el punto de vista semántico, ya en el primer capítulo queda delimitada la problemática del ensayo, con una construcción que apela a una amplia variedad de vocablos evocadores del sexo-género femenino.

De todos modos, además del significado de las palabras dentro del sistema y del sentido que estas adquieren en su uso, la producción discursiva implica la aplicación de mecanismos gramaticales y sintácticos, como veremos seguidamente.

\subsection{El opacamiento de las mujeres}

A continuación comentamos algunos ejemplos de Le deuxième sexe sobre el uso de reglas gramaticales y sintácticas y su consecuencia en la visualización del género gramatical femenino.

CAGNOLATI, FEMENÍAS, VUKOVIC. Simone de Beauvoir en Argentina: el rol de las editoriales y de las traducciones en la recepción de su obra

Belas Infiéis, v. 8, n. 2, pp. 31-49, 2019. DOI: 10.26512/belasinfieis.v8.n2.2019.24372 
En el primer capítulo, verificamos la preferencia por anteposición del masculino en los casos de coordinación: mâles et femelles/ machos y hembras (14 ocurrencias); hommes et femmes/hombres y mujeres ( 2 ocurrencias). En contraposición, el género femenino antepuesto al masculino se presenta en dos coordinaciones cuyo primer miembro es numéricamente mayor que el segundo: il meurt 128 filles pour 100 garçons (BEAUVOIR, 1949, p. 77) / mueren 128 niñas por cada 100 varones (Trad. de Palant 1954, I, p. 61).

Se aprecia también un uso frecuente de sustantivos epicenos tanto en francés como en la traducción de Palant (individu-s/individuo-s; sujet/sujeto; foetus/feto; être-s humain-s/ser-es humano-s), genéricos (homme-s/hombre-s) y de invariables en francés (un-des enfant-s) cuya reexpresión en castellano fluctúa entre los genéricos niño-s/ hijo-s, como vemos a continuación:

(8) On a longtemps pensé, on pense encore dans certaines sociétés primitives à filiation utérine, que le père n'a aucune part dans la conception de l'enfant (BEAUVOIR, 1949, I, p. 51).

(9) Se ha pensado durante mucho tiempo, y aún se piensa en ciertas sociedades primitivas de filiación uterina, que el padre no tiene participación alguna en la concepción del niño (BEAUVOIR. Trad. de Palant, 1954, I, p. 33).

(10) [...] il est rare qu'il s'intéresse directement aux enfants. (BEAUVOIR, 1949, I, p.74).

(11) $[\ldots]$ es raro que se interese directamente en los hijos. (BEAUVOIR. Trad. de Palant, 1954, I, p.48).

En cuanto a la célebre afirmación On ne naît pas femme, on le devient (BEAUVOIR, 1949, II, p.6), Palant la traduce «No se nace mujer: llega una a serlo» (1954, II, p.13); en cambio, tanto García Puente (2007, p. 207) como Alicia Martorell (2011, p. 371) se deciden por la expresión «No se nace mujer: se llega a serlo».

La formulación original de S. de Beauvoir ha hecho correr ríos de tinta en el campo de los Estudios de Género, con la consiguiente proliferación de propuestas, más allá de las traducciones consagradas al castellano ya citadas. Dentro de la variedad de reformulaciones difundidas, tomamos las siguientes: a. «Una no nace, sino que se convierte en mujer» (LAMAS, 1999); b. «Una no nace mujer, se hace mujer» (SÁNCHEZ MORA, 2004, p. 52); c. «La mujer no nace mujer, se hace mujer» (MARTÍNEZ, 2014).

El pronombre indefinido francés on en función sujeto encierra una inespecificidad referencial, lo cual posibilita una serie de reexpresiones en castellano, ya sea la partícula impersonal «se» o bien pronombres indefinidos portadores de género gramatical, como es el caso de «una», «uno». En las reformulaciones que nos ocupan, aparece una gama de recursos que combinan las formas más indefinidas ya sea con una única ocurrencia del vocablo «mujer» 
(casos a), con dos (b), o bien realizan una correferencialidad manifiesta acumulando tres veces la palabra «mujer» $(\mathrm{c})$.

Las reglas gramaticales francesas indican que el pronombre indefinido francés on realiza la concordancia en masculino singular, pero también admite la variación por silepsis en femenino y plural. Tanto en el original francés como en la traducción, en el primer capítulo solo se registra la concordancia en masculino Si l'on est un peu scrupuleux, (1949, I, p. 58) / Quien sea un poco escrupuloso, (1954, I, p. 38).

En la misma línea de borramiento del género gramatical, observamos el pronombre francés nous en función sujeto cuya concordancia está dada por plural masculino: nous nous trouvons placés devant un fait (1949, I, p. 53) / nos encontramos situados frente a un hecho (1954, I, p. 33).

Desde la óptica ensembliste o integradora (LAROSE, 1989, p. 223), las expresiones y contenidos microestructurales sufren la tensión de otros niveles superiores, textuales y peritextuales: la traducción se convierte en una serie de toma de decisiones de quien traduce mediada por su ethos y por el respeto a las normas (TOURY, [1995] 2004, p. 97-107). Los casos analizados del original francés muestran que la novedad temática de Simone de Beauvoir no apela a recursos linguístico-discursivos de ruptura, sino que se pliega a las reglas gramaticales y sintácticas clásicas imperantes en la cultura de aquel momento. Su obra se ubica en una época en la que aún no se ha instalado el interés por eliminar las huellas sexistas ni tampoco por subvertir el lenguaje patriarcal para reivindicar las ideas feministas. Una conducta similar adopta la traducción de Palant (1954), con lo cual acerca su producción al texto original o polo origen según la norma de adecuación, en términos de Toury ([1995] 2004, p. 98).

\section{Conclusiones}

Como hemos visto es posible identificar la recepción e influencia de la obra de Simone de Beauvoir en la producción intelectual de un conjunto de mujeres ensayistas-literarias, en especial en Argentina, con proyección en toda América Latina y España, como Silvina Bullrich, María Rosa Oliver, Salvadora Medina Onrubia, Emma Barrandéguy, Beatriz Guido, Alejandra Pizarnik, Aurora Venturini, Martha Lynch, Sara Gallardo, entre otras. En la década del 60, puede detectarse su presencia en filósofas como Lucía Piossek Prebisch, en especial en su tratamiento sobre «La mujer y la filosofía», publicado originalmente en Sur (PIOSSEK, 19701971; FEMENÍAS, 2008; SMALDONE, 2013).

CAGNOLATI, FEMENÍAS, VUKOVIC. Simone de Beauvoir en Argentina: el rol de las editoriales y de las traducciones en la recepción de su obra 
El impacto en un público amplio de la obra novelística de Beauvoir, con su estilo fenomenológico de escritura, la minuciosidad de sus relatos y la agudeza de su mirada, fue sumamente importante. Otro tanto sucedió con sus ensayos, desde El Segundo Sexo a Por una moral de la ambigüedad, donde analiza la noción de «situación» en disidencia con Sartre. Ahora bien, desde un punto de mira teórico-conceptual, metodológico y hermenéutico, su obra más resonante fue Le deuxième sexe (LÓPEZ PARDINA, 1998), y sobre ella nos hemos centrado para ilustrar tanto la importancia del trabajo de traducción como sus límites lexicales y epocales. No obstante, sabemos que el grado de descripción de la traducción de Le deuxième sexe, y del amplio espectro de conceptos y términos específicos que incluye, no se limita a unos pocos ejemplos, como los que hemos ofrecido, en el marco de la cultura receptora de su tiempo. Por ello es interesante atender a las consecuencias que acarrean las transformaciones que dificultan la aceptación de una traducción a la luz de las lecturas actuales. El recurso y necesidad de cotejo de las traducciones con la obra en su lengua fuente y la consideración de las relecturas críticas al hilo de los nuevos desarrollos teóricos plantean la necesidad y el desafío de una revisión más o menos sistemática de las traducciones con que contamos. En suma, porque estas relecturas

44 posibilitan a un tiempo nuevos puentes de análisis, que ponen en evidencia una vez más la originalidad y el impacto renovados del pensamiento beauvoiriano, y la distancia teórica que su obra, como fundamento de tales recorridos, habilita.

\section{Apéndice}

Presentamos, a continuación, la nómina de las obras de Simone de Beauvoir, que hemos utilizado como fuente, y cuyas traducciones fueron realizadas en Argentina:

(1943) L 'invitée. Paris: Gallimard. (1953) La invitada. Trad. de Silvina Bullrich. Buenos Aires: Emecé.

(1944) «Pyrrhus et Cinéas», en Pour une morale de l'ambigüité. Paris: Gallimard. (1965) Para qué la acción. Trad. de Juan José Sebreli. Buenos Aires: Ediciones Siglo Veinte.

(1945) Le sang des autres. Paris: Gallimard. (1955) La sangre de los otros. Trad. de Hellén Ferro. Buenos Aires: Schapire.

(1945) Les bouches inutiles. Paris: Gallimard. (1957) Las bocas inútiles. Trad. de Floreal Mazia. Buenos Aires: Ariadna.

(1946) Tous les hommes sont mortels. Paris: Gallimard. (1951) Todos los hombres son mortales. Trad. de Silvina Bullrich. Buenos Aires: Emecé.

(1946) «Littérature et métaphysique». Les Temps Modernes, № 7, abril 1946, p. 1153-1163.

(1947) «Literatura y metafísica». Trad. de María Rosa Oliver. Sur, no 147-149, p. 287-301.

(1947) Pour une morale de l'ambiguïté. Paris: Gallimard. (1956) Para una moral de la ambigüedad. Trad. de Francisco Jorge Solero. Buenos Aires: Schapire. 
(1948) L'Amérique au jour le jour. Paris: Gallimard. (1964) Norteamérica al desnudo. Trad. de Juan José Sebreli. Buenos Aires: Ediciones Siglo Veinte.

(1948) L'existentialisme et la sagesse des nations. Paris: Gallimard. (1965) El existencialismo y la sabiduría de los pueblos. Trad. de Juan José Sebreli. Buenos Aires: Siglo Veinte. (2008) Trad. de Horacio Pons. Edhasa.

(1949) Le deuxième sexe. Paris: Gallimard, v. I. (1954). El segundo sexo. Trad. de Pablo Palant. Buenos Aires: Psique. v. 1 y 2. (2007) El segundo sexo. Trad. de Juan García Puente Buenos Aires: Sudamericana. Primera edición 1999.

(1954) Les Mandarins. Paris: Gallimard. (1958) Los mandarines. Trad. de Silvina Bullrich. Buenos Aires: Sudamericana.

(1958) Mémoires d'une jeune fille rangée. Paris, Gallimard. (1959) Memorias de una joven formal. Trad. de Silvina Bullrich. Buenos Aires: Sudamericana.

(1960) La force de l'âge. Paris, Gallimard. (1966) La plenitud de la vida. Trad. de Silvina Bullrich. Buenos Aires: Sudamericana.

(1960) La force des choses. Paris: Gallimard. (1964) La fuerza de las cosas. Trad. de Ezequiel de Olaso. Buenos Aires: Sudamericana.

(1964) Une mort très douce. Paris: Gallimard. (1965) Una muerte muy dulce. Trad. de María Elena Santillán. Buenos Aires: Sudamericana.

(1966) Les belles images. Paris: Gallimard. (1967) Hermosas imágenes. Trad. de José Bianco. Buenos Aires: Sudamericana.

(1967) La Femme rompue. Paris: Gallimard. (1968) La mujer rota. Trad. de Dolores Sierra y Néstor Sánchez. Buenos Aires: Sudamericana.

(1970) La vieillesse. Paris: Gallimard. (1970) La vejez. Trad. de Aurora Bernárdez. Buenos Aires: Sudamericana.

(1972) Tout compte fait. Paris: Gallimard. (1972) Final de cuentas. Trad. de Ida Vitale. Buenos Aires: Sudamericana.

(1981) La cérémonie des adieux suivi d'Entretiens avec Jean-Paul Sartre (Août - septembre 1974). Paris: Gallimard. (1983) La ceremonia del adiós seguido de "Conversaciones con JeanPaul Sartre, agosto-septiembre de 1974». Trad. de J. Sanjosé Carbajosa. Buenos Aires: Sudamericana.

\section{BIBLIOGRAFÍA}

ALTAMIRANO, Carlos; MYERS, Jorge. Historia de los intelectuales en América Latina. Buenos Aires: Katz, 2008.

AUGÉ, Claude; AUGÉ, Paul. Larousse Classique Illustré. Nouveau Dictionnaire

Encyclopédique. Paris : Librairie Larousse, 1951.

BEAUVOIR, Simone de. Le deuxième sexe. Paris: Gallimard, v. I, 1949. Disponible en: https://www.scribd.com/document/375689973 Último acceso: 31 jul. 2018.

BEAUVOIR, Simone de. Le deuxième sexe. Paris: Gallimard, v. II, 1949. Disponible en: https://www.scribd.com/document/375689999 Último acceso: 31 jul. 2018.

BEAUVOIR, Simone de. El segundo sexo. Traducido por: Pablo Palant. Buenos Aires: Psique, 1954. Título original: Le deuxième sexe.

CAGNOLATI, FEMENÍAS, VUKOVIC. Simone de Beauvoir en Argentina: el rol de las editoriales y de las traducciones en la recepción de su obra

Belas Infiéis, v. 8, n. 2, pp. 31-49, 2019. DOI: 10.26512/belasinfieis.v8.n2.2019.24372 
BEAUVOIR, Simone de. El segundo sexo. Traducido por: Juan García Puente. Buenos Aires: Sudamericana, [1999] 2011. Título original: Le deuxième sexe.

BEAUVOIR, Simone de. El segundo sexo. Traducido por: Alicia Martorell. Madrid: Cátedra, 2011. Título original: Le deuxième sexe.

BULLRICH, Silvina. Mis Memorias. Buenos Aires: Emecé, 1980.

BUTLER, Judith. Sexo y género en El segundo sexo de Simone de Beauvoir. Mora, n.4, Editorial de la Facultad de Filosofía y Letra-UBA. Traducido por: María Luisa Femenías. Buenos Aires: UBA, 1998. Título original: «Sex and Gender in Simone de Beauvoir's Second Sex» (1986).

BUTLER, Judith. Imitación e insubordinación de género. Revista de Occidente, n. 235, p. 85$109,2000$.

CAGNOLATI, Beatriz; FORTE MÁRMOL, Amalia; GENTILE, Ana María; VIEGUER, Fabiana. De la Argentina al mundo hispanoamercano: las traducciones con acento porteño de Simone de Beauvoir. En: CAGNOLATI, Beatriz y FEMENÍAS, Ma. Luisa (comps.). Las encrucijadas de «el otro sexo», La Plata: Edulp, 2010. p. 13-15.

CAGNOLATI, Beatriz, FEMENÍAS, María Luisa; SMALDONE, Mariana. Le deuxième 46 sexe: des marques épocales dans la traduction de «travestie ». En: CORBI SAEZ, M. I.; LORCA TONDA, M. A. (ed.). Simone de Beauvoir. Lectures actuelles et regards sur l'avenir // Simone de Beauvoir. Today's readings and glances on the future. Bern: Peter Lang, 2015.

CORBÍ SÁEZ, María Isabel. Simone de Beauvoir: sus obras traducidas y su recepción en la prensa. Feminismo/s, n. 15, p. 165-191, 2010.

CORREAS, Carlos. Operación Masotta: cuando la muerte también fracasa. Buenos Aires: Interzona, 2007.

FEMENÍAS, María Luisa. Simone de Beauvoir: hacer triunfar el reino de la libertad.

Oficios Terrestres, Revista de la FPCC, UNLP, n. XIV.23, p. 32-45, 2008.

FEMENÍAS, María Luisa. Sobre sujeto y género. Lecturas feministas de Beauvoir a Butler. Buenos Aires: Catálogos, 2000. Reeditado en Rosario: Prohistoria, 2013.

FEMENÍAS, María Luisa. Judith Butler: una introducción a su lectura. Buenos Aires: Catálogos, 2003.

FERRERO, Adrián. Narrar el feminismo: teoría crítica, trasposición y representación literaria en la obra de Simone de Beauvoir. En: CAGNOLATI, Beatriz; FEMENÍAS, Ma. Luisa (comps.). Las encrucijadas de «el otro sexo», La Plata: Edulp, 2010. p. 103-123.

FOUCAULT, Michel. Microfísica del poder. Madrid: La Piqueta. 1992. 
KING, John. Sur: estudio de la revista literaria argentina y de su papel en el desarrollo de una cultura, 1931-1970. México: Fondo de Cultura Económica, 1989.

LAMAS, Marta (1999). Una no nace, sino que se convierte en mujer. La Jornada Semanal, 24 de enero de 1999. Disponible en: www.jornada.com.mx/1999/01/24/sem-lamas.html Último acceso: 15 jul. 2018.

LAROSE, Robert. Théories contemporaines de la traduction. Québec: PUQ, 1989. LÓPEZ PARDINA, Teresa. Simone de Beauvoir: Una filósofa del siglo XX. Cádiz: Universidad de Cádiz, 1998.

MARTÍNEZ, Pablo. La verdad sobre la igualdad sexual. Xátiva (Valencia): Editorial Planeta Alvi, 2014. Disponible en: https://books.google.com.ar/books?isbn=1502383683 Último acceso: 15 jul. 2018.

MUCCI, Cristina. La gran burguesa. Una biografía de la escritora Silvina Bullrich. Buenos Aires: Editorial Norma, 2003. Disponible en: www.cristinamucci.com.ar/descargas/La-Gran-Burgesa-E-Book-Revisado.pdf Último acceso: 15 jul. 2018.

OLIVER, María Rosa. Mundo, mi casa. Buenos Aires: Falbo Librero Editor, 1965. PARODI LISI, Maria Cristina. El proyecto cultural de la revista Sur (1931-1970) en la obra literaria de Victoria Ocampo. Berlín: Darmstadt, 1987.

PIOSSEK PREBISCH, Lucía. La mujer y la filosofía. Sur, n. 326-328, p. 95-101, 1970-1971. REAL ACADEMIA ESPAÑOLA Y ASOCIACIÓN DE ACADEMIAS DE LA LENGUA ESPAÑOLA. Diccionario de la lengua española Edición del Tricentenario. Madrid:

Espasa, 2014, actualización 2017. Disponible en: http://dle.rae.es Último acceso: 18 jul. 2018.

SÁNCHEZ MORA, Ana María. La ciencia y el sexo. México: UNAM, 2004. Disponible en: https://books.google.com.ar/books/about/La_ciencia_y_el_sexo.html?id=Zdtl-

KigGmIC\&redir_esc=y Último acceso 15 jul. 2018.

SMALDONE, Mariana. Una tesis innovadora en la Argentina de los sesenta: fenomenología de la maternidad. Diálogo con Lucía Piossek Prebisch. Mora, n. 19, Editorial de la Facultad de Filosofía y Letra-UBA, p.127-136, 2013.

SMALDONE, Mariana.Las traducciones rioplatenses de Le deuxième sexe de Simone de Beauvoir: marcas de época en torno a la enunciación de identidades generizadas. Mutatis Mutandis, n. 8 (2), p. 394-416, 2015. Disponible en:

https://aprendeenlinea.udea.edu.co/revistas/index.php/mutatismutandis/article/view/24117 Último acceso: 15 jul. 2018.

SMALDONE, Mariana.Representaciones «femeninas» en la producción literaria de escritoras argentinas entre los años 50' y 60'. Aproximaciones desde la intersección de género, clase y etnia como aporte a la educación en géneros y sexualidades. Tesis de Especialización en Educación en Géneros y Sexualidades, dirigida por Beatriz Cagnolati. Secretaría de Posgrado de la Facultad de Humanidades y Ciencias de la Educación, La Plata:

CAGNOLATI, FEMENÍAS, VUKOVIC. Simone de Beauvoir en Argentina: el rol de las editoriales y de las traducciones en la recepción de su obra

Belas Infiéis, v. 8, n. 2, pp. 31-49, 2019. DOI: 10.26512/belasinfieis.v8.n2.2019.24372 
Universidad Nacional de La Plata, 2017. Disponible en:

http://sedici.unlp.edu.ar/handle/10915/66037 Último acceso: 15 jul. 2018.

SMALDONE, Mariana.Conciencia y concienciación en Simone de Beauvoir:

Entrecruzamientos de género y clase y la recepción inmediata en Argentina. Tesis de Licenciatura, dirigida por María Luisa Femenías. Departamento de Filosofía, Facultad de Filosofía y Letras, Universidad de Buenos Aires, 2016. Inédito.

TOURY, Gideon. Los estudios descriptivos de traducción y más allá. Metodología de la investigación en Estudios de Traducción. Traducido por: Rosa Rabadán y Raquel Merino. Madrid: Cátedra, [1995] 2004. p. 94-107. Título original: Descriptive Translation Studies and Beyond.

VIEIRA BORGES, Joana. Trajetórias e Leituras feministas no Brasil e na Argentina. Tesis de Doctorado. (Portaria ${ }^{\circ}$ 006/PPGH/2013), Centro de Filosofia e Ciências Humanas, Programa de Pós-Graduaçao em História. Universidade de Santa Catarina, Florianópolis, 19 mar. de 2013. Inédito.

VON FLOTOW, Luise. «Gender and Translation». En: KUHIWCZAK, P.; LITTAU, K. (ed.). A Companion to Translation Studies. Clevedon, Reino Unido: Multilingual Matters Ltd, 2007.

48 WILLSON, Patricia. La constelación del sur, traductores y traducciones en la literatura argentina del siglo XX. Buenos. Aires: Siglo XXI, 2004.

WILLSON, Patricia. Traductores en el siglo, Punto de vista, n.87, p. 19-25, 2007.

${ }^{1}$ Beatriz Emilce CAGNOLATI - Doctora en Letras, Profesora en Lengua y Literatura Francesas, Traductora Pública de Francés. Facultad de Humanidades y Ciencias de la Educación (FaHCE). Universidad Nacional de La Plata (UNLP). Docencia: Profesora titular Traducción Científico-Técnica en Francés II y Gramática Contrastiva francés/castellano. FaHCE. UNLP. Investigación: Directora de Proyectos de Investigación y Desarrollo; Coordinadora del Área de Investigación en Traductología. Instituto de Investigaciones en Humanidades y Ciencias Sociales (IdIHCS). Consejo Nacional de Investigaciones Científicas y Técnicas (CONICET). UNLP. Argentina. Universidad Nacional de La Plata. Buenos Aires, Argentina.

ORCID: https://orcid.org/0000-0003-0626-1183

E-mail: beatrizcagnolati@gmail.com

Sitio académico:: http://www.memoria.fahce.unlp.edu.ar/perfiles/0227CagnolatiB.html

2 María Luisa FEMENÍAS - Doctora en Filosofía (UCM), Profesora Consulta de la Universidad Nacional de La Plata (2016). Co-editora de la revista Mora (UBA) entre 1993-2017. Profesora visitante en numerosas Universidades del país y del exterior. Premio Konex a la Trayectoria Académica (2006-2016), Profesora Distinguida UBA (2017), Doctora Honoris Causa, UNC. (2017). Se destacan las siguientes publicaciones: Sobre Sujeto y Género (Re)lecturas feministas de Beauvoir a Butler ([2000], 2011), El género del multiculturalismo ([2007], 2013) y Los ríos subterráneos (2013-2018) seis volúmenes sobre violencia contra las mujeres. También ha compilado (en colaboración): Judith Butler, su filosofía a debate, (2013); Judith Butler: Las identidades del sujeto opaco, (2015); Antropología filosófica (para no filósofos) (2016) y Judith Butler fuera de sí (2017), entre otros. Universidad Nacional de La Plata. Universidad Nacional de Quilmes. Buenos Aires, Argentina.

ORCID: http://orcid.org/0000-0003-1144-1197

E-mail: mlfeme@yahooo.com.ar

Sitio académico:: http://www.memoria.fahce.unlp.edu.ar/perfiles/0494FemeniasM.html

CAGNOLATI, FEMENÍAS, VUKOVIC. Simone de Beauvoir en Argentina: el rol de las editoriales y de las traducciones en la recepción de su obra

Belas Infiéis, v. 8, n. 2, pp. 31-49, 2019. DOI: 10.26512/belasinfieis.v8.n2.2019.24372 
3 Jovanka VUKOVIC - Profesora Titular de Traducción Científico Técnica en Inglés I y II, en la carrera de Traductor Público de la Facultad de Humanidades y Cs. de la Educación, Prof. Titular, Inglés, Bellas Artes, Prof. Titular Inglés Médico, facultad de Cs. Médicas UNLP; Directora de cursos de Inglés Técnico e Instrumental I y II para las Carreras de Postgrado y Residencia Médicas de la Facultad de Cs. Médicas y Docente Investigadora categorizada III, Área de Investigación Traductológica (AIT- FaHCE- UNLP). Presidenta desde 2016 del Colegio de Traductores Públicos e Intérpretes de la Provincia de Buenos Aires, Argentina. Universidad Nacional de La Plata. Buenos Aires, Argentina.

ORCID: https://orcid.org/0000-0002-6195-3900

E-mail: jovanka.vukovic1@gmail.com

Sitio académico:: http://www.memoria.fahce.unlp.edu.ar/perfiles/1417VukovicJ.html 